\title{
Buscando respuestas a los tres grandes hitos de la Música en los últimos 70 años en una asignatura de master
}

\section{Amparo Porta}

Universitat Jaume I. Castellón. España. porta@edu.uji.es

\begin{abstract}
Resumen
Tres son los grandes hitos de la música desde el ámbito educativo conseguidos en los últimos 70 años. El primero, la importancia y significatividad del contexto, el segundo es la importancia comunicativa de la música y el tercero, la naturaleza mediadora de los signos poseedores de significado y sentido social. A partir de estos tres parámetros nos preguntamos de qué música hablamos, dónde está situada qué significa, a quien o qué representa y qué efectos produce?Los resultados muestran las percepciones de la música de los partiipantes en diferentes contextos. Todo ello considerado desde su posición en la docencia como espacio de innovación e investigación educativa en educación superior.
\end{abstract}

Palabras clave: Educación musical, Análisis de contenido, Didáctica, Métodos mixtos

\section{Introducción}

La educación musical ha ido evolucionando a lo largo del tiempo y actualmente nos movemos, como el resto de áreas de conocimiento, en un espacio sujeto a cambios constantes. Uno de los máximos hallazgos de la educación del S. XX fue colocar al sujeto en el contexto dando así un paso más a los grandes avances logrados con la Escuela Nueva (Giroux \& Mur Ubasart,1998; Wertsch, Ramírez Garrido, Zanón, \& Cortés, 1988)). Esta posición del sujeto que aprende inmerso en el contexto, no tiene un tratamiento sencillo, de hecho estamos de manera permanente tratando de encontrar formas de dialogo.

El objetivo de este trabajo es analizar la percepción de siete contextos musicales por estudiantes de postgrado especializado en estudios de master a través de dos objetivos específicos: 
1. Explorar y analizar diferentes entornos musicales por medio de visionados

2. Realizar un análisis de contenido y sus comparaciones con los resultados obtenidos sobre el debate generado.

Todo ello realizado individualmente, en grupos de trabajo y como resultados de síntesis finales de la acción en nivel de master

\subsection{Marco Teórico}

Los cambios acontecidos en el último siglo obligan a un movimiento hacia adelante en la acción didáctica del siglo XXI. Esta necesidad de avance sustantivo, con unos cambios sin precedentes en la Historia de la Música, requiere conocer cuales son sus espacios y contenidos vivos en la acción educativa. Así, hablamos del contexto social, académico, digital, mediático, de la producción musical, la recepción y la audiencia, el espacio de la música tradicional y culta, sus poblaciones, impulsores, la industria y otros muchos. Este escenario hace necesario observar la música como un gran territorio, utilizado y generado desde distintos dominios, miradas y acciones. La aproximación a este mundo complejo y multifacético no es sencilla, necesita, para que sea veraz y eficaz, responder a la sociedad de la que surge. Para ello se hace necesario utilizar una metodología que, partiendo del contacto directo, proporcione una serie de indicadores con los que operar de manera representativa para definirla y analizarla. A lo largo de nuestra trayectoria hemos estudiado las distintas formas de aproximación desde la Música, la Sociología, la Psicología Cognitiva y la Semiótica. En este caso nos acercaremos a través del análisis de contenido de los diferentes sectores contextuales que queremos analizar (Porta, 2007, 2014, 2016)]

\subsubsection{Aproximación meodológica}

La forma de aproximación requiere repensar, no tanto el concepto de música como los espacios que le dan soporte y vida, creando redes y enjambres que muestran por donde la música circula y se instala en la práctica totalidad de los espacios culturales. De esta forma el escenario se amplia a la práctica totalidad de las actividades humanas. Por esa razón, los entorno sonoros también lo son de aprendizaje, y la Didáctica de la Música necesita ampliar su cobertura para explorar sus territorios. Todo ello hace necesaria una triangulación metodológica cuyos grandes pilares son el Lenguaje de la Música porque la música habla desde ella, la Sociología porque se dirige a los espacios sociales, masivos en muchas ocasiones, y, finalmente, la Semiótica porque tiene significación para cada uno (Porta, 2007, 2014) 


\subsubsection{El contexto y la Didáctica de la Música}

El sujeto y su contexto han sido dos ejes de transformación de la educación en el S. XX en el aprendizaje significativo ha tenido u (Ausubel, 1976) así como con el estudio y significado del aprendizaje escolar Coll (1988). Por todo ello, nuestra línea investigadora se interesa por posición del sujeto en el discurso disciplinar, académico, social, patrimonial de la Didáctica de la Música. Y en ella se considera

El sujeto: aquel al que va dirigido o sufre sus efectos

El discurso: el conglomerado de signos (Talens, Romera \& Tordera, 1978)

El sentido: la posición del sujeto en su hábitat sonoro.

Finalmente, destacamos como último elemento de nuestra fundamentación teórica, la naturaleza mediadora de los signos poseedores de significado y el carácter social de la conciencia (Vigotsky, Carrasco Iriarte \& Ausín, 2008). A partir de estos presupuestos y mirando los espacios profesionales, elementales y obligatorios de la música desde la formación de su profesorado nos preguntamos en nuestra acción formativa de la Música en la Educación Superior.

¿De qué música hablamos? ¿Dónde está situada? ¿Qué significa? ¿A quien o qué representa? ¿Qué efectos produce?

Para poder contestarlas, necesitamos del análisis e interpretación de la música desde una posición ampliada requiere para su comprensión de: 1) Análisis de contenido, 2) Análisis del discurso y 3) la aplicación de procesos inductivos basados en la Teoría Fundamentada.

\section{Metodología}

\subsection{Finalidad}

Para dar respuesta al objetivo, 24 estudiantes de master con titulación superior de conservatorio estudiaron y debatieron a partir de secuencias musicales visionadas en Mp4. Se grabó el contenido de la sesión en cuya discusión se les invitó a hablar de música desde distintas vertientes: la propia música, el público, el escenario, la preparación y la difusión. Una vez transcrito dicho debate, se aplicó el análisis de contenido siendo sus resultados tratados de forma estadística y como análisis de texto con soporte informático. 


\subsection{Muestra}

Los 30 estudiantes participantes tenían entre 24 y 55 años con un 65,2\% de hombres y 34,8 65 mujeres. Fue realizado en una asignatura de master universitario de educación musical. Las secuencias fueron visionadas colectivamente y analizadas inicialmente de manera individual, posteriormente en grupo y finalmente se recogieron los resultados finales. La actividad se desarrolló precedida de una presentación teórica sobre la aproximación al tema "Dando visibilidad a los contextos en los estudios de la música" en la asignatura "Lecturas del Habitat sonoro"

\subsection{Procedimiento}

Se desarrollaron cuatro tareas en cuatro sesiones de dos horas de trabajo cada una :

Tarea 1. Búsqueda de elementos musicales en diferentes audiovisuales, codificación de elementos y creación de categorías a través de procesos inductivos basados en la Teoría Fundamentada (Strauss, A., \& Corbin, J. M. (1990).

Tarea 2. Visionado y análisis individual de siete contextos musicales y análisis de cinco categorías: Música, escenario, publico, preparación y difusión.

Tarea 3. Creación de mapas colectivos por grupos de trabajo

Tarea 4. Análisis de grupos, contextos y categorías

La tarea 1 tuvo carácter preliminar. En ella se realizo una exploración introductoria en la que los estudiantes tenían que clasificar en códigos y subcodigos los indicadores o conceptos seleccionados previamente, a partir del visionado de escenas musicales en diferentes audiovisuales.

\subsection{Preguntas y cuestiones clave}

¿Qué ves y escuchas? En la música, en el escenario, en el público

Qué piensas sobre la preparación de lo que acabas de ver: personas, estudios necesarios, medios económicos y humanos, impacto social,...La difusión y cobertura 


\subsubsection{Tabla 1 .}

Se muestra la Plantilla para la clasificación completa con palabras que indiquen aspectos sustanciales o características (Tabla 1)

Tabla 1.

\begin{tabular}{l|l|l|l|l|l|l|l}
\hline \hline & $m c 1$ & $m c 2$ & $m c$ 3 & $m c 4$ & $m c 5$ & $m c$ 6 & $m c 7$ \\
\hline Música & & & & & & & \\
\hline Escenario & & & & & & & \\
\hline Público & & & & & & & \\
\hline Preparación & & & & & & & \\
\hline Difusión & & & & & & & \\
\hline Otros & & & & & & & \\
\hline \hline
\end{tabular}

Tabla 1 Plantilla para la clasificación completa con palabras que indiquen aspectos sustanciales o características

Font: Elaboración propia

\section{Resultados}

El análisis de contenido queda plasmado en una serie de mapas y gráficas que muestran cada una de las categorías así como el análisis de se presencia ponderada en cada uno de ellos. Los resultados revelan la presencia de elementos de la música y sus entornos que pueden utilizarse en la docencia, la innovación y la investigación educativa como indicadores. Estos elementos destacados no aparecen normalmente en las acciones formativas en los ámbitos universitarios. Este primer trabajo sobre los elementos destacados del debate prepara las acciones necesarias para establecer estudios comparados que pongan en relación la vida social y curricular o académica de la música. 


\subsection{Resultados individuales por nubes de palabras}

Para realizarlo se ha utilizado la aplicación Word Cloud Generator

\subsubsection{Música}

La percepción del concepto música por los estudiantes, todos ellos titulados superiores de Conservatorio fue la de mayor número de aportaciones. Destacan la tímbrica representada por familias: cuerda, viento, voz, elementos estilísticos y objetos con significación muy específica de la música como es el caso de la batuta. En la nube de palabras, destacan los instrumentos acústicos; en los géneros y tipologías musicales aparecen la música tradicional, clásica y el pop y, finalmente, como elementos específicos del siglo XX, la grabación y el altavoz. En resumen los mapa mental construido por el conjunto de los estudiantes de música, por individualidades a partir del visionado de las cinco obras en sus contextos muestran una percepción, al menos docente, claramente inclinada hacia los elementos acústicos de la música y las familias instrumentales reconocidas, sin referencias al lenguaje musical ni a los elementos o estructuras musicales, y apareciendo la música de los siglos XX y XXI con menor énfasis. (Figura 1).

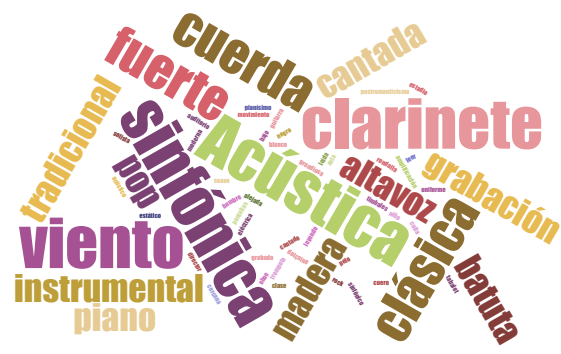

Fig. 1 Música

Font: Propia

\subsubsection{Escenario}

El escenario percibido incluye elementos más modernos en líneas generales como son: imágenes, pantallas, enchufes, cables así como referencias a tamaños y condiciones de iluminación (Figura 2) 


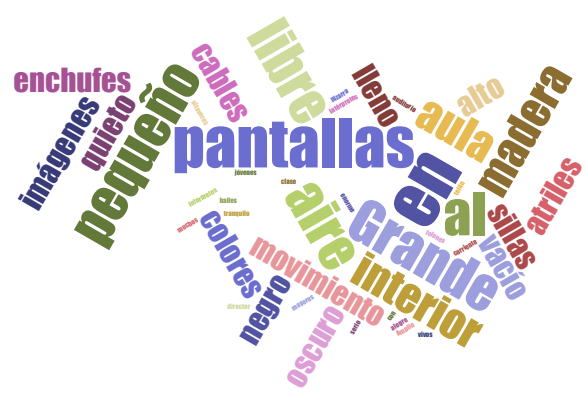

Fig. 2 Escenario

Font: Propia

\subsubsection{El público}

En relación al público la nube de palabras grupal destaca una mayor referencia a los sectores populares que a los entornos académicos y cultos de la música como pudieran ser respetuoso, silencioso, arreglado, butacas, pelo blanco, en oposición a multitudinario, joven, agitado, informal, agitado, saltando.

\subsubsection{Preparación}

Aparecen con una presencia similar los grandes polos referidos al tiempo de preparación de los conciertos clásicos con respecto a las grandes producciones y entornos del pop-rock.

\subsubsection{Difusión}

Finalmente la difusión percibida indica los grandes medios de comunicación social con una representación alta, y en un grado mucho más bajo las menciones a los sistemas utilizados tradicionalmente por la música y otras manifestaciones hasta la mitad del siglo XX como son los programas, carteles, con la familia, revistas y periódicos, el boca a boca y una mayor presencia de los grandes medios como son radio TV (Figura 3) 


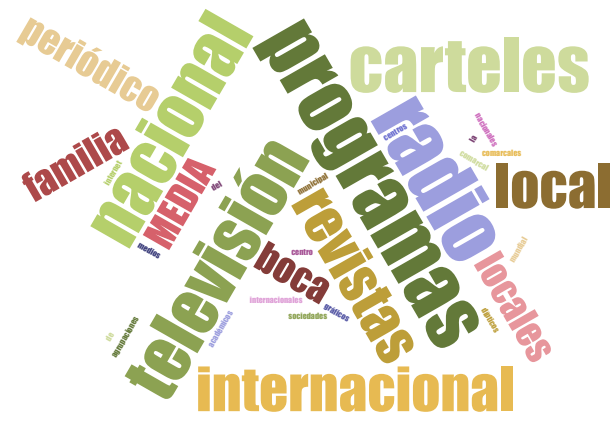

Fig. 3 Difusión

Font: Propia

\subsection{Resultados obtenidos por grupos y categorías}

Table 2. Resultados por grupos y categorías

\begin{tabular}{l|c|c|c|c|c}
\hline \hline Muestra & Música & Escenario & Público & Preparación & Difusión \\
\hline G1 & 6,6 & 10 & 0 & 42,4 & 9 \\
\hline G2 & 0 & 27,27 & 0 & 33,3 & 0 \\
\hline G 3 & 14,28 & 8,33 & 0 & 37,5 & 12,5 \\
\hline G 4 & 6,6 & 7,14 & 0 & 60 & 0 \\
\hline G 5 & 6,25 & 8,33 & 0 & 50 & 0 \\
\hline G 6 & 17,6 & 15,38 & 0 & 75 & 10 \\
\hline \hline
\end{tabular}

\section{Conclusiones}

La mirada de la Psicología Cognitiva, la Pedagogía Crítica, la Sociología de la Música y la Semiótica han sido la disciplinas de las que nos hemos nutrido para este acercamiento que, finalmente, ha dado lugar al recorrido que presentamos.

A través de todo ello nos hemos aproximado al perfil del estudiante de postgrado en Música y comprobado cómo lo que más actúa en él a la hora de analizar la música es lo que conoce de ella. Por ello es necesario realizar aproximaciones analíticas a los contextos de la música como espacios de reflexión y aprendizaje con objeto de ampliar el foco de la Didáctica de la Música. 


\section{Agradecimientos}

Unitat de Suport Educatiu. USE. Universitat Jaume I. Castellón

\section{Referencias}

Adorno, T. W. (2009). Disonancias/Introducción a la sociología de la música (Vol. 14). Ediciones AKAL.

Cisneros Puebla, C. A. (2003). Computer-assisted qualitative analysis. Sociologías, (9), 288-313.

Giroux, H. A., \& Mur Ubasart, M. (1998). La escuela y la lucha por la ciudadanía: pedagogía crítica de la época moderna.

Greimas, A. J., \& Muñoz, J. A. A. (1980). Semiótica y ciencias sociales. Fragua, Madrid

Myers, M. D. (1997). Qualitative research in information systems. Management Information Systems Quarterly, 21(2), 241-242.

Porta, (2016). La competencia comunicativa en educación musical. Definición, presencia y repercusiones en Libro de Actas III Congreso Nacional de Conservatorios Superiores de Música: SEM, Noja

Porta, 2014 Formación, investigación y difusión científica: los grandes retos para el avance y reconocimiento de la educación musical. Boletin SEM, 17-18: SEM. Noja

Porta, A. (2007). Músicas públicas, escuchas privadas: hacia una lectura de la música popular contemporánea. Universitat Autònoma de Barcelona, Servei de Publicacions.

Sloboda, J. A. (1985). The musical mind: The cognitive psychology of music. Oxford University Press.

Strauss, A., \& Corbin, J. M. (1990). Basics of qualitative research: Grounded theory procedures and techniques. Sage Publications, Inc.

Talens, J., Romera, J., \& Tordera, A. (1978). Elementos para una semiótica del texto artístico. Poesía, narrativa, teatro, cine, Madrid, Cátedra.

Vigotsky, L. S., Carrasco Iriarte, H., \& Ausín, T. (2008). Pensamiento y lenguaje: teoría del desarrollo cultural de las funciones.

Wertsch, J. V., Ramírez Garrido, J. D., Zanón, J., \& Cortés, M. (1988). Vygotsky y la formación social de la mente. 